\title{
Society of Thoracic Surgeons 2008 cardiac risk models predict in-hospital mortality of heart valve surgery in a Chinese population: A multicenter study
}

\author{
Lv Wang, MD, ${ }^{\mathrm{a}, \mathrm{b}}$ Fang-Lin Lu, MD, PhD, ${ }^{\mathrm{a}}$ Chong Wang, MD, PhD, ${ }^{\mathrm{a}}$ Meng-Wei Tan, MD, PhD, ${ }^{\mathrm{a}}$ and \\ Zhi-yun $\mathrm{Xu}, \mathrm{MD}, \mathrm{PhD}^{\mathrm{a}}$
}

\begin{abstract}
Objectives: The Society of Thoracic Surgeons 2008 cardiac surgery risk models have been developed for heart valve surgery with and without coronary artery bypass grafting. The aim of our study was to evaluate the performance of Society of Thoracic Surgeons 2008 cardiac risk models in Chinese patients undergoing single valve surgery and the predicted mortality rates of those undergoing multiple valve surgery derived from the Society of Thoracic Surgeons 2008 risk models.
\end{abstract}

\begin{abstract}
Methods: A total of 12,170 patients underwent heart valve surgery from January 2008 to December 2011. Combined congenital heart surgery and aortal surgery cases were excluded. A relatively small number of valve surgery combinations were excluded. The final research population included the following isolated heart valve surgery types: aortic valve replacement, mitral valve replacement, and mitral valve repair. The following combined valve surgery types were included: mitral valve replacement plus tricuspid valve repair, mitral valve replacement plus aortic valve replacement, and mitral valve replacement plus aortic valve replacement and tricuspid valve repair. Evaluation was performed by using the Hosmer-Lemeshow test and C-statistics.
\end{abstract}

Results: Data from 9846 patients were analyzed. The Society of Thoracic Surgeons 2008 cardiac risk models showed reasonable discrimination and poor calibration (C-statistic, 0.712; $P=.00006$ in Hosmer-Lemeshow test). Society of Thoracic Surgeons 2008 models had better discrimination (C-statistic, 0.734) and calibration $(P=.5805)$ in patients undergoing isolated valve surgery than in patients undergoing multiple valve surgery (C-statistic, 0.694; $P=.00002$ in Hosmer-Lemeshow test). Estimates derived from the Society of Thoracic Surgeons 2008 models exceeded the mortality rates of multiple valve surgery (observed/expected ratios of 1.44 for multiple valve surgery and 1.17 for single valve surgery).

Conclusions: The Society of Thoracic Surgeons 2008 cardiac surgery risk models performed well when predicting the mortality for Chinese patients undergoing valve surgery. The Society of Thoracic Surgeons 2008 models were suitable for single valve surgery in a Chinese population; estimates of mortality for multiple valve surgery derived from the Society of Thoracic Surgeons 2008 models were less accurate. (J Thorac Cardiovasc Surg 2014;148:3036-41)

The Society of Thoracic Surgeons (STS) Predicted Risk of Mortality (PROM) is a standard risk prediction algorithm for patients undergoing isolated coronary artery bypass grafting (CABG), isolated valve replacement, and CABG plus valve replacement and is based on the STS National Adult Cardiac Surgery Database, one of the largest specialty-specific clinical data registries in the world with periodic updates and revisions. The recent STS 2008

From the Department of Cardiac and Thoracic Surgery, ${ }^{a}$ Changhai Hospital, Second Military Medical University, Shanghai, China; and Department of Cardiac and Thoracic Surgery, ${ }^{\text {b }}$ No 252 Hospital, Baoding, Hebei, China.

Disclosures: Authors have nothing to disclose with regard to commercial support.

Drs Lv Wang, Fang-Lin Lu, and Chong Wang contributed equally.

Received for publication Dec 14, 2012; revisions received Aug 2, 2013; accepted for publication Sept 10, 2013; available ahead of print Aug 3, 2014.

Address for reprints: Zhi-yun Xu, MD, PhD, Department of Cardiothoracic Surgery, Changhai Hospital, Second Military Medical University, 174 Changhai Rd,

Shanghai 200433, China (E-mail: zhiyunx@hotmail.com).

$0022-5223 / \$ 36.00$

Copyright (c) 2014 by The American Association for Thoracic Surgery

http://dx.doi.org/10.1016/j.jtcvs.2013.09.081 cardiac surgery risk models were published in 2009, based on STS National Adult Cardiac Surgery Database version 2.61. They include new valve and valve plus CABG surgery models that differentiate between mitral valve replacement (MVR) and repair $^{1}$ and show great improvement in model discrimination compared with the previous STS risk models. ${ }^{2-4}$

The STS-PROM and the European System for Cardiac Operation Risk Evaluation (euroSCORE), another successful risk evaluation system used worldwide, have clearly demonstrated good predictive ability when applied to patients with coronary artery disease. ${ }^{5,6}$ Recent studies concerning valve surgery mortality have shown that STSPROM outperforms not only the euroSCORE but also other cardiac risk prediction models, such as the Ambler score, Providence score, and Veterans Administration score, when applied to aortic valve replacement (AVR)..$^{7-10}$

Rheumatic heart disease, which usually affects heart valves, is the primary reason for heart surgery in China. 


\section{Abbreviations and Acronyms \\ AVR = aortic valve replacement \\ $\mathrm{CABG}=$ coronary artery bypass grafting \\ $\mathrm{CI}=$ confidence interval \\ euroSCORE $=$ European System for Cardiac \\ Operation Risk Evaluation \\ MVR = mitral valve replacement \\ MVRepair = mitral valve repair \\ $\mathrm{O} / \mathrm{E} \quad=$ observed/expected \\ PROM = Predicted Risk of Mortality \\ STS $=$ Society of Thoracic Surgeons \\ TVRepair $=$ tricuspid valve repair}

Multiple valve surgery for rheumatic heart disease comprises approximately two fifths of all heart valve surgery procedures in China. The aim of this study was to validate the STS 2008 cardiac risk models in a contemporary group of patients undergoing heart valve surgery, including AVR, MVR, mitral valve repair (MVRepair), AVR + MVR, MVR + tricuspid valve repair (TVRepair), and MVR + AVR + TVRepair, and to evaluate whether STS-PROM accurately predicts in-hospital mortality in a Chinese population. Although the STS 2008 risk models were not designed for multiple valve surgery, we decided to study their performance in both the Chinese isolated and multiple valve populations. For multiple valve surgery, if they perform acceptably, they could be used until formal STS risk models for multiple valve procedures are released.

\section{PATIENTS AND METHODS}

\section{Patient Population and Data}

In the current study, all adult patients who underwent heart valve surgery between January 2008 and December 2011 at 4 cardiac surgery centers were included: Fu Wai Hospital in Beijing, Changhai Hospital of Shanghai, Zhongshan Hospital of Fudan University in Shanghai, and Cuangdong Cardiovascular Institute in Guangzhou. To meet all requirements for the STS 2008 models, we excluded patients with concomitant aortic or congenital heart surgery. Patients who underwent isolated heart valve surgery other than AVR, MVR, and MVRepair also were excluded. Combined valve surgery other than MVR plus TVRepair, AVR plus MVR, and AVR plus MVR and TVRepair were excluded because of their relatively small numbers.

Information on patients and the procedural risk factors for all patients were collected retrospectively, resulting in a completely retrospective dataset stored in a local cardiac valve database. Patients who underwent single valve surgery were separated from those who underwent multiple valve surgery; thus, 2 patient groups were created in this database. The predictive mortality rate for every patient in this study was calculated using the published STS 2008 cardiac surgery risk models, including their risk factor definition and predictive risk calculation formula. ${ }^{2,3}$ Because valve surgery combined with CABG accounted for a small fraction of the total valve surgery procedures, valve surgery combined with and without CABG was merged for model validation. In-hospital mortality was the dependent variable in this study.

\section{Data Analysis}

The discriminatory power of the model was assessed with the C-statistic (index of concordance) and 95\% confidence intervals (CIs). The $\mathrm{C}$-statistic, or area under the receiver operating characteristic curve, is the proportion of predictions that are concordant with the observations. The value of the C-statistic ranges from 0.5 (no ability to discriminate) to 1.0 (full ability to discriminate). The discriminative power of the model is considered reasonable when the C-statistic is more than 0.7 and strong when the $\mathrm{C}$-statistic exceeds $0.8 .^{11}$ Model calibration was evaluated by the Hosmer-Lemeshow goodness-of-fit test. All statistical analyses were performed with SPSS version 19.0 (SPSS Inc, Chicago, Ill).

\section{RESULTS \\ Patient Population}

All 12,157 patients who underwent valve surgery procedures between January 2008 and December 2011 were evaluated for study inclusion. Valve surgery combined with aortic surgery and congenital heart procedures were excluded from the dataset. AVR, MVR, MVRepair, MVR plus TVRepair, MVR plus AVR, MVR plus AVR, and TVRepair were included in this study, and they accounted for approximately $81 \%$ of all valve surgery procedures during this study. Finally, a database including 9846 patients was obtained. The baseline patient characteristics of our study population and those of the STS 2008 cardiac surgery risk models are shown in Table 1 . The operation details for our study population are shown in Table 2.

\section{Model Validation}

The observed in-hospital mortality was $1.79 \%$ in all patients (176 deaths in 9846 patients), and the predicted mortality was $1.33 \%$; the overall observed/expected $(\mathrm{O} / \mathrm{E})$ ratio of in-hospital mortality was 1.34 . In-hospital mortality was $1.38 \%$ in the single valve surgery group (54 deaths in 3917 patients) and $2.06 \%$ in the multiple valve surgery group (122/5929 patients). The predicted mortalities were $1.18 \%$ and $1.43 \%$, respectively. The $\mathrm{O} / \mathrm{E}$ ratios of operative mortalities were 1.17 and 1.44 , respectively.

Discrimination. The C-statistics for the overall patient population, the single valve surgery group, and the multiple valve surgery group are shown in Table 2. The STS 2008 risk models showed better performance in the single valve group (C-statistic, 0.734) than in the multiple valve group (C-statistic, 0.694). Figure 1 shows the receiver operating characteristic curves for the single valve surgery group, multiple valve surgery group, and overall study population. Calibration. The $P$ values of the Hosmer-Lemeshow goodness-of-fit tests for all patients, the single valve surgery group, and the multiple valve surgery group were .0000645 , .58 , and .018 , respectively (Table 3 ). The STS 2008 risk models proved to be well calibrated for the single valve surgery group, whereas the derived estimates were poorly 
TABLE 1. Distribution of risk factors in our study population versus Society of Thoracic Surgeons 2008 models

\begin{tabular}{|c|c|c|c|c|}
\hline \multirow[b]{2}{*}{ Variable } & \multicolumn{2}{|c|}{$\begin{array}{c}\text { No. of } \\
\text { patients }\end{array}$} & \multicolumn{2}{|c|}{$\begin{array}{l}\text { Proportion of risk factors present } \\
\text { in STS } 2008 \text { risk models }\end{array}$} \\
\hline & $\mathbf{N}$ & $\%$ & $\begin{array}{l}\text { Isolated valve } \\
\text { surgery }(\%)\end{array}$ & $\begin{array}{c}\text { Valve surgery } \\
\text { plus CABG }(\%)\end{array}$ \\
\hline All patients & 9846 & 100 & $\mathrm{n}=109,759$ & $\mathrm{n}=101,661$ \\
\hline \multicolumn{5}{|l|}{ Age (y) } \\
\hline$<55$ & 6182 & 62.8 & 25.6 & 6.6 \\
\hline $55-64$ & 2733 & 27.8 & 21.2 & 16.9 \\
\hline $65-74$ & 865 & 8.7 & 25.6 & 33.1 \\
\hline$\geq 75$ & 66 & 0.7 & 27.5 & 43.4 \\
\hline \multicolumn{5}{|l|}{ Sex } \\
\hline Male & 4458 & 45.3 & 55.4 & 64.5 \\
\hline Female & 5388 & 54.7 & 44.6 & 35.5 \\
\hline \multicolumn{5}{|c|}{ Body surface area $\left(\mathrm{m}^{2}\right)$} \\
\hline$<1.50$ & 2310 & 23.5 & 4.0 & 3.3 \\
\hline $1.50-1.74$ & 4876 & 49.5 & 22.4 & 20.4 \\
\hline $1.75-1.99$ & 2360 & 24.0 & 36.9 & 39.4 \\
\hline$\geq 2.00$ & 300 & 3.0 & 36.0 & 36.4 \\
\hline \multicolumn{5}{|c|}{ Body mass index $\left(\mathrm{kg} / \mathrm{m}^{2}\right)$} \\
\hline$<25$ & 7609 & 77.3 & 32.4 & 28.9 \\
\hline $25-29$ & 2034 & 20.7 & 35.6 & 38.7 \\
\hline $30-34$ & 191 & 1.9 & 18.7 & 20.7 \\
\hline$\geq 35$ & 12 & 0.1 & 12.5 & 11.0 \\
\hline \multicolumn{5}{|c|}{ Renal function (creatinine, $\mathrm{mg} / \mathrm{dL}$ ) } \\
\hline$<1.00$ & 7488 & 76.0 & 38.3 & 29.7 \\
\hline $1-1.49$ & 2197 & 22.3 & 47.3 & 51.2 \\
\hline $1.5-1.99$ & 114 & 1.2 & 7.4 & 11.3 \\
\hline $2-2.49$ & 33 & 0.3 & 1.8 & 2.7 \\
\hline$\geq 2.5$ & 14 & 0.1 & 1.2 & 1.6 \\
\hline \multicolumn{5}{|c|}{ No. of diseased coronary vessels } \\
\hline 0 & 9627 & 97.7 & 82.3 & 2.3 \\
\hline 1 & 107 & 1.1 & 8.2 & 22.3 \\
\hline 2 & 112 & 1.1 & 3.1 & 26.7 \\
\hline 3 & 0 & 0 & 5.1 & 48.3 \\
\hline \multicolumn{5}{|l|}{ Ejection fraction $\%$} \\
\hline$<25$ & 5 & 0.1 & 2.5 & 5.7 \\
\hline $25-34$ & 71 & 0.7 & 5.4 & 10.8 \\
\hline $35-44$ & 371 & 3.8 & 9.1 & 14.7 \\
\hline $45-54$ & 1359 & 13.8 & 18.7 & 20.1 \\
\hline$\geq 55$ & 8040 & 81.7 & 55.5 & 42.8 \\
\hline \multicolumn{5}{|l|}{ NYHA } \\
\hline I & 2211 & 22.5 & 15.9 & 9.7 \\
\hline II & 2889 & 29.3 & 29.5 & 24.4 \\
\hline III & 4382 & 44.5 & 36.7 & 41.9 \\
\hline IV & 364 & 3.7 & 13.1 & 20.2 \\
\hline Combined CABG & 359 & 3.6 & & \\
\hline
\end{tabular}

calibrated for the multiple valve surgery group and the overall group. The calibration plots (observed vs expected) are presented in Figure 2.

The clinical performance of the STS 2008 cardiac surgery risk models was tested for patients with different predicted mortality (Figure 3). The overall population and
TABLE 2. Operation details for the study population

\begin{tabular}{lcc}
\hline & Frequency & Proportion (\%) \\
\hline AVR & 1830 & 18.6 \\
MVR & 1475 & 15.0 \\
MVRepair & 612 & 6.2 \\
MVR + TVRepair & 2828 & 28.7 \\
MVR + AVR & 1201 & 12.2 \\
MVR + AVR + TVRepair & 1900 & 19.3 \\
\hline
\end{tabular}

$A V R, A$ ortic valve replacement; $M V R$, mitral valve replacement; $M V R e p a i r$, mitral valve repair; TVRepair, tricuspid valve repair.

the 2 subgroups were divided into quintiles according to their STS-predicted mortality. Then the observed mortality was compared with the predicted mortality. The best agreement between observed and expected mortality was achieved in patients in the single valve surgery group with mild-to-moderate predicted mortality risk (between $0.5 \%$ and $1 \%$ ). An approximate prediction was found for low-risk patients in the overall population with predicted mortality less than $0.9 \%$. The STS produced a predicted mortality lower than the observed mortality in patients at high to very high risk in both the single valve surgery group and the multiple valve surgery group.

\section{DISCUSSION}

The main results of our study are that (1) the STS 2008 cardiac surgery risk models can be used as a risk prediction tool for patients in a Chinese population undergoing cardiac valve surgery and that (2) the STS 2008 cardiac surgery models and the derived estimates show more predictive

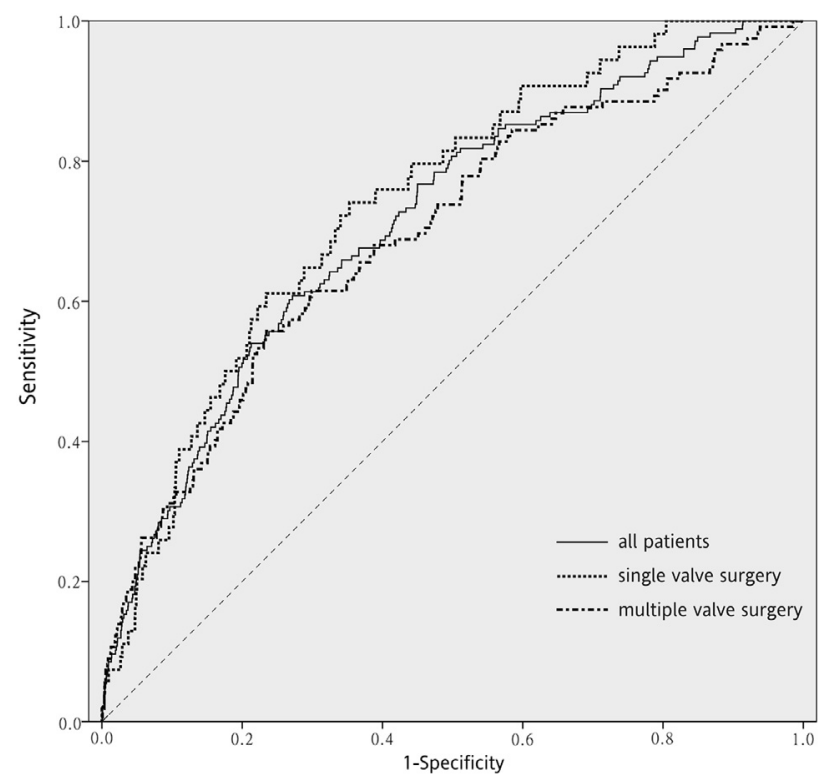

FIGURE 1. Receiver operating characteristic curve of STS 2008 models for valve surgery: all patients, 0.712 ; single valve surgery group, 0.734 ; multiple valve surgery group, 0.694 . 
TABLE 3. Mortality predictive statistics of Society of Thoracic Surgeons 2008 models for the study population

\begin{tabular}{lcccc}
\hline & C-statistic & $\begin{array}{c}\text { P value of Hosmer-Lemeshow } \\
\text { goodness-of-fit test }\end{array}$ & $\begin{array}{c}\text { Observed } \\
\text { mortality (\%) }\end{array}$ & $\begin{array}{c}\text { Expected } \\
\text { mortality (\%) }\end{array}$ \\
\hline All procedures & $0.712(0.647-0.750)$ & .00006 & 1.79 & 1.33 \\
Single valve surgery & $0.734(0.670-0.799)$ & .5805 & 1.38 & 1.34 \\
Multiple valve surgery & $0.694(0.644-0.744)$ & .00002 & 2.06 & 1.18 \\
\hline
\end{tabular}

O/E, Observed/expected.

power for single valve procedures than multiple valve procedures.

The STS-PROM is one of the most widely used risk prediction tools for patients undergoing cardiac surgery. It plays an important role in current clinical practice and has been used to predict postoperative risk, stratify "high-risk" patients for alternative therapy strategies, and evaluate the impact of risk factors on operation outcomes ${ }^{12}$ and as a benchmark for hospital performance. ${ }^{13}$ With its high degree of accuracy, the model also became the entry criteria for patients in the Transcatheter Aortic Valve Implantation device trial in the United States. Because the published STS 2008 cardiac surgery risk models have not been well validated in a Chinese population, it is meaningful to evaluate whether the STS 2008 cardiac surgery risk models can provide sufficient predictive power for Chinese patients undergoing valve surgery. Our study population was selected from 4 institutions located in East China, the developed area of China, and the population was drawn from approximately half of the area of China. We believe that our study results are representative of the Chinese population.

In regard to the ethnicity, epidemiology, and medical treatment difference between patients in our institutions and patients in the STS database, the baseline characteristics in our institutions differed from those of the STS population. The population included in our study was younger and had less renal dysfunction, higher ejection fractions, less coronary artery disease, and better New York Heart Association levels than those in the STS models (Table 1). There were more patients with a low risk of in-hospital death in our study population and fewer at high risk (patients with predicted hospital mortality $>10 \%$ accounted for $0.25 \%$ of study population). These differences may account for some of the decreased predictive power of the STS-PROM in our overall study population.

The STS-PROM underestimated the mortality $(\mathrm{O} / \mathrm{E}$ ratio of 1.34) of the overall study population. The C-statistic was 0.712 (95\% CI, 0.674-0.750), and the Hosmer-Lemeshow test demonstrated a lack of calibration $(P=.0000645)$. The internal model discrimination of the STS 2008 models was strong for the isolated valve surgery model (C-statistic, 0.799 in the validation sample and 0.805 in the development sample) and good in valve surgery plus CABG (C-statistic, 0.750 in the validation sample and 0.754 in the development sample). ${ }^{2-4}$ This demonstrated that the STS 2008 cardiac risk models have less discriminatory power in our study population than in the STS population. A validation of the euroSCORE in Chinese patients undergoing valve surgery was performed by Wang and colleagues ${ }^{14}$ and resulted in poor predictive power; the STS 2008 models showed a better performance than the euroSCORE in Chinese patients undergoing valve surgery (C-statistic, 0.712 for STS 2008 models in this study vs 0.64 for the euroSCORE in their study). Taken together, the STS 2008 models are
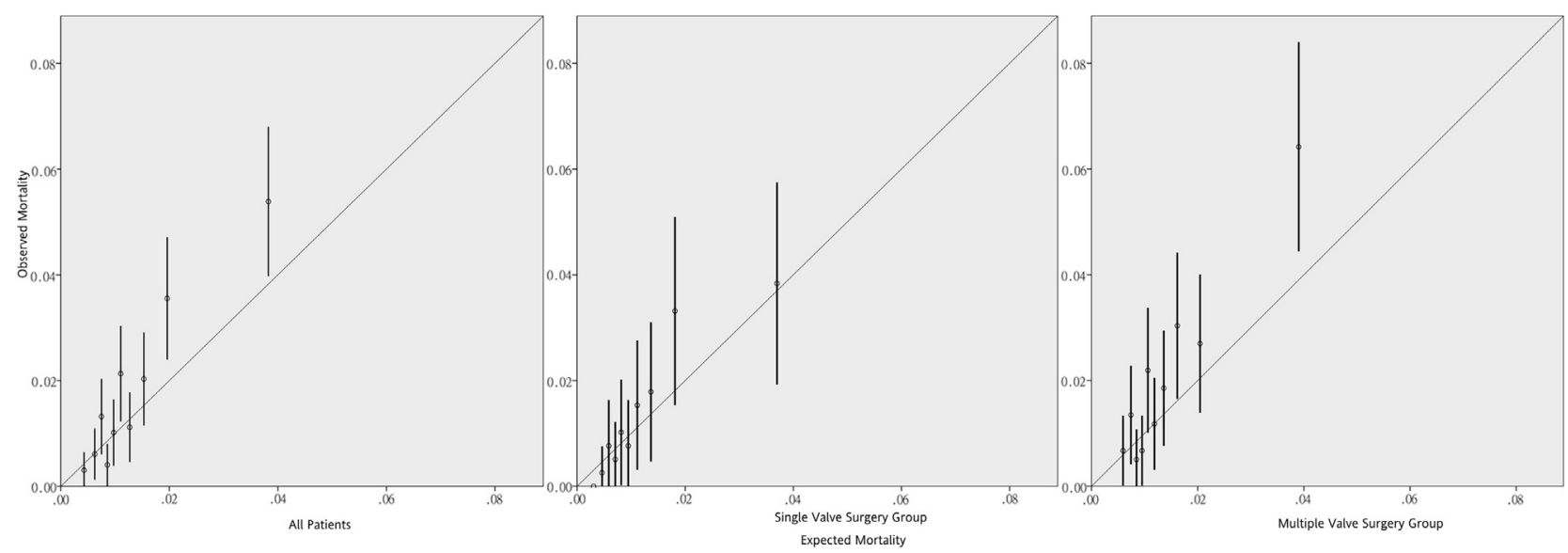

FIGURE 2. Calibration plots of STS 2008 risk models: The calibration plots of STS 2008 for the single valve surgery group were closer to a straight line that exceeds $45^{\circ}$ than calibration plots for all patients and the multiple valve group. 


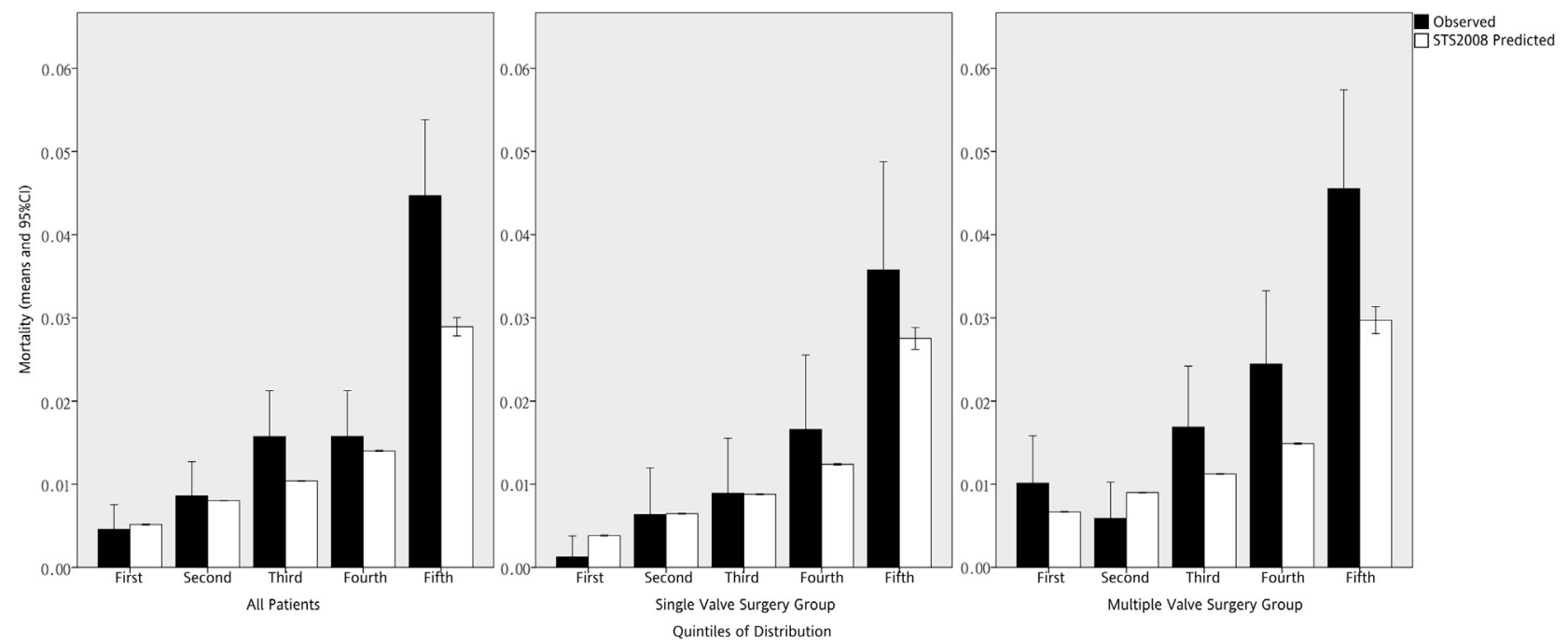

FIGURE 3. Clinical performance of STS 2008 models for patient subgroups according to mortality risk. CI, Confidence interval; STS, Society of Thoracic Surgeons.

good risk prediction tools for China, especially for patients undergoing single valve surgery, with STS-predicted mortality ranging from $0.5 \%$ to $1 \%$.

Rheumatic heart disease, which does not influence a particular valve, remains the key cause of heart valve disease at our institutions. Multiple valve procedures are common, because MVR + AVR + TVRepair, MVR + TVRepair, and MVR + AVR account for approximately $49.8 \%$ of all valve procedures in our study population. Multiple valve procedures were not included in the STS 2008 cardiac surgery models because that accounted for a small number of procedures in the STS database, and the risk prediction algorithm of single valve surgery may lead to a decrease in predictive power if applied in multiple valve surgery. Therefore, we validated single valve procedures and multiple valve procedures separately. The C-statistic was 0.734 (95\% CI, 0.670-0.799), the $P$ value of the Hosmer-Lemeshow goodness-of-fit test was .58, and the $\mathrm{O} / \mathrm{E}$ ratio was 1.18 in the single valve surgery group; this means that the STS-PROM fits well with our study population for single valve surgery in both discrimination and calibration. Studying model validation in aortic valve surgery ${ }^{10}$ suggested that the STS-PROM showed better discrimination than the euroSCORE in predicting hospital mortality (C-statistic, 0.73 for STS 2008 models vs 0.68 for euroSCORE). This result was similar to that of our study, because single valve procedures showed a C-statistic of 0.734 , which was not as good as that in the STS population (C-statistics of 0.805 for development sample and 0.799 for validation sample in the isolated valve group, 0.754 for development sample, and 0.750 in validation sample in the valve plus $\mathrm{CABG}$ group) ${ }^{2,3}$

In this study, validation of the STS 2008 models in the multiple valve surgery group showed poor discrimination
(C-statistic, 0.678; 95\% CI, 0.628-0.729), poor calibration (Hosmer-Lemeshow test: $P=.018$ ), and significantly overestimated mortality (O/E 1.43). Multiple valve surgery was more complex than single valve surgery, and the cardiopulmonary bypass times usually were longer, leading to increased injury to the myocardium. Recent studies indicate that cardiopulmonary bypass time was a significant early mortality risk factor in patients undergoing $\mathrm{CABG}$ or valve surgery. ${ }^{15,16}$ Pulmonary artery hypertension was proved to be a risk factor to the outcome of aortic valve surgery, ${ }^{17}$ and the absence of pulmonary artery hypertension in the STS 2008 risk models might be part of the reason that it had relatively poor performance in our study population. The absence of a complexity factor for the surgical procedures presented in the STS 2008 models may be the reason that the STS 2008 models are inferior with multivalve procedures. The complexity of the procedure is a predictor of operative mortality in the euroSCORE II ${ }^{18}$ but is not considered in STS 2008 models. The creators of the STS 2008 models used another method to resolve complexity; they established specific models for each procedure: isolated valve surgery, $\mathrm{CABG}$, and valve surgery plus $\mathrm{CABG}$. The specificity of these models might restrict the application of STS 2008 models to other types of cardiac surgery.

\section{Study Limitations}

This study validated only mortality; 8 of the 9 other end points that the STS cardiac surgery risk models provide were not validated. Combined valve surgery and CABG accounted for approximately $3 \%$ of our study population, so this group could not be accurately validated in this study. For the reasons mentioned, the true performance of the STS 2008 cardiac risk models in the Chinese population may have been biased. 


\section{CONCLUSIONS}

The STS 2008 cardiac surgery risk models are an excellent risk-evaluation system for assessing the risk of morbidity and mortality after cardiac surgery, including valve surgery, $\mathrm{CABG}$, and valve surgery and CABG together. The STS 2008 cardiac risk models performed well when predicting the mortality for Chinese patients who underwent valve surgery. As the baseline characteristics differed in the study populations and STS population, the STS 2008 models were more suitable for single valve surgery than for multiple valve surgery in a Chinese population.

\section{References}

1. Shahian DM, Edwards FH. The Society of Thoracic Surgeons 2008 cardiac surgery risk models: introduction. Ann Thorac Surg. 2009;88(1 Suppl):S1.

2. Shahian DM, O'Brien SM, Filardo G, Ferraris VA, Haan CK, Rich JB, et al. The Society of Thoracic Surgeons 2008 cardiac surgery risk models: part 3-valve plus coronary artery bypass grafting surgery. Ann Thorac Surg. 2009;88(1 Suppl):S43-62.

3. O'Brien SM, Shahian DM, Filardo G, Ferraris VA, Haan CK, Rich JB, et al. The Society of Thoracic Surgeons 2008 cardiac surgery risk models: part 2-isolated valve surgery. Ann Thorac Surg. 2009;88(1 Suppl):S23-42.

4. Shahian DM, O'Brien SM, Filardo G, Ferraris VA, Haan CK, Rich JB, et al. The Society of Thoracic Surgeons 2008 cardiac surgery risk models: part 1coronary artery bypass grafting surgery. Ann Thorac Surg. 2009;88(1 Suppl): S2-22.

5. Ad N, Barnett SD, Speir AM. The performance of the EuroSCORE and the Society of Thoracic Surgeons mortality risk score: the gender factor. Interact Cardiovasc Thorac Surg. 2007;6:192-5.

6. Farrokhyar F, Wang X, Kent R, Lamy A. Early mortality from off-pump and onpump coronary bypass surgery in Canada: a comparison of the STS and the EuroSCORE risk prediction algorithms. Can J Cardiol. 2007;23:879-83.

7. Dewey TM, Brown D, Ryan WH, Herbert MA, Prince SL, Mack MJ. Reliability of risk algorithms in predicting early and late operative outcomes in high-risk patients undergoing aortic valve replacement. J Thorac Cardiovasc Surg. 2008; 135:180-7.

8. Tran HA, Roy SK, Hebsur S, Barnett SD, Schlauch KA, Hunt SL, et al. Performance of four risk algorithms in predicting intermediate survival in patients undergoing aortic valve replacement. Innovations (Phila). 2010;5:407-12.

9. Wendt D, Osswald BR, Kayser K, Thielmann M, Tossios P, Massoudy P, et al Society of Thoracic Surgeons score is superior to the EuroSCORE determining mortality in high risk patients undergoing isolated aortic valve replacement. Ann Thorac Surg. 2009;88:468-75.

10. Basraon J, Chandrashekhar YS, John R, Agnihotri A, Kelly R, Ward H, et al Comparison of risk scores to estimate perioperative mortality in aortic valve replacement surgery. Ann Thorac Surg. 2011;92:535-40.

11. Hosmer DW, Lemeshow S. Assessing the fit of the model. In: Shewhart WA Wilks SS, eds. Applied Logistic Regression. Hoboken, NJ: John Wiley \& Sons, Inc; 2005:143-202.

12. Rankin JS, Hammill BG, Ferguson TB Jr, Grover FL, Grunkemeier GL, Naftel DC, et al. Determinants of operative mortality in valvular heart surgery. J Thorac Cardiovasc Surg. 2006;131:547-57.

13. Shahian DM, Blackstone EH, Edwards FH, Grover FL, Grunkemeier GL, Naftel DC, et al. Cardiac surgery risk models: a position article. Ann Thorac Surg. 2004;78:1868-77.

14. Wang C, Yao F, Han L, Zhu J, Xu ZY. Validation of the European system for cardiac operative risk evaluation (EuroSCORE) in Chinese heart valve surgery patients. J Heart Valve Dis. 2010;19:21-7.

15. Anderson AJ, Barros Neto FX, Costa Mde A, Dantas LD, Hueb AC Prata MF. Predictors of mortality in patients over 70 years-old undergoing CABG or valve surgery with cardiopulmonary bypass. Rev Bras Cir Cardiovasc. 2011;26:69-75.

16. Gunay R, Sensoz Y, Kayacioglu I, Tuygun AK, Balci AY, Kisa U, et al. Is the aortic valve pathology type different for early and late mortality in concomitant aortic valve replacement and coronary artery bypass surgery? Interact Cardiovasc Thorac Surg. 2009;9:630-4.

17. Kennedy JL, LaPar DJ, Kern JA, Kron IL, Bergin JD, Kamath S, et al. Does the Society of Thoracic Surgeons risk score accurately predict operative mortality for patients with pulmonary hypertension? J Thorac Cardiovasc Surg. 2013;146: 631-7.

18. Nashef SA, Roques F, Sharples LD, Nilsson J, Smith C, Goldstone AR, et al. EuroSCORE II. Eur J Cardiothorac Surg. 2012;41:734-45. 